\title{
Updating the Simulation Effectiveness Tool: Item Modifications and Reevaluation of Psychometric Properties
}

\author{
Kim Leighton \\ Patricia K. Ravert \\ Brigham Young University - Provo, patricia-ravert@byu.edu \\ Vickie Mudra \\ Chamberlain College of Nursing \\ Christopher Macintosh \\ University of Utah
}

Follow this and additional works at: https://scholarsarchive.byu.edu/facpub

Part of the Other Nursing Commons

\section{Original Publication Citation}

Leighton, K., Ravert, P., Mudra, V., Macintosh, C. Updating the simulation effectiveness tool: Item modifications and reevaluation of psychometric properties. Nursing Education Perspectives. 35(5), 317-323.

\section{BYU ScholarsArchive Citation}

Leighton, Kim; Ravert, Patricia K.; Mudra, Vickie; and Macintosh, Christopher, "Updating the Simulation Effectiveness Tool: Item Modifications and Reevaluation of Psychometric Properties" (2015). Faculty Publications. 5285.

https://scholarsarchive.byu.edu/facpub/5285

This Peer-Reviewed Article is brought to you for free and open access by BYU ScholarsArchive. It has been accepted for inclusion in Faculty Publications by an authorized administrator of BYU ScholarsArchive. For more information, please contact ellen_amatangelo@byu.edu. 


\title{
Updating the Simulation
}

Effectiveness Tool: Item

Modifications and Reevaluation

of Psychometric Properties

\author{
Kim Leighton, Patricia Ravert, Vickie Mudra, and Christopher Macintosh
}

doi: $10.5480 / 15-1671$

\section{Abstract}

AIM This study evaluated the psychometric properties of the modified Simulation Effectiveness Tool (SET), the SET-M.

BACKGROUND The SET, developed in 2005, was updated to be consistent with INACSL Standards of Best Practice, QSEN practices, and American Association of Colleges of Nursing baccalaureate essentials.

METHOD Undergraduate nursing students from two nursing programs, one with multiple campuses, completed the SET-M following completion of a simulated clinical experience; 1,288 students took part in the study.

RESULTS Exploratory factor analysis was completed using unweighted least squares. Four subscales were identified with acceptable internal consistency: Prebriefing $(\alpha=.833)$, Learning $(\alpha=.852)$, Confidence $(\alpha=.913)$, and Debriefing $(\alpha=.908)$.

CONCLUSION Revisions made to modify the SET to current standards of simulation practice have resulted in the SET-M, which has been shown to be a valid and reliable method of evaluating students' perceptions of the effectiveness of learning in the simulation environment.

While the use of manikin-based simulation has grown at a rapid pace in undergraduate nursing education, lack of rigorous tool development to evaluate effectiveness has been a shortcoming in implementation (KardongEdgren, Adamson, \& Fitzgerald, 2010). The Simulation Effectiveness Tool (SET) was developed to address that shortcoming and has been used by educators worldwide for a decade (Elfrink Cordi, Leighton, Ryan-Wenger, Doyle, \& Ravert, 2012).

While the use of the SET demonstrated acceptable reliability and validity, our understanding of simulation and best practices has changed since the SET was originally developed. The International Nursing Association for Clinical Simulation and Learning (INACSL) published the first Standards of Best Practice: Simulation in 2011, with updates and new guidelines released in 2013 (INACSL Board of Directors, 2013). These Standards clarified terminology and further defined recommended simulation processes, such as prebriefing. The purpose of this study was twofold: to revise the SET items to be more congruent with current simulation standards and practices and examine psychometric properties of the Simulation Effectiveness Tool-Modified (SET-M).

\section{LITERATURE REVIEW}

Nehring (2010) analyzed 13 available research studies on nursing student outcomes following simulated clinical experiences (SCEs); outcomes included satisfaction, self-confidence, self-ratings, knowledge, and skill performance. A meta-analysis of nursing simulation literature by Lapkin, Levett-Jones,
Bellchambers, and Fernandez (2010) revealed only eight studies, and these evaluated critical thinking, skills performance, and knowledge. Further analysis outside the nursing literature revealed similar findings: few studies, poor quality of the study design, and conflicting terminology interfered with determining overall effectiveness of simulation as a teaching methodology (Cook et al., 2011; McGaghie, Issenberg, Petrusa, \& Scalese, 2010). In addition to small sample sizes, inadequate power and lack of reliability and validity analysis have yielded few evaluation tools that are appropriate for measuring outcomes of simulation education (Hayden, Smiley, Alexander, Kardong-Edgren, \& Jeffries, 2014).

There are many challenges associated with instrument development, particularly when 


\section{Table 1: Comparison of SET and SET-M Items with Rationale for Change and Subscale Identification}

\section{Original SET Item (with Subscales)}

- I feel more confident that I will be able to recognize changes in my real patient's condition (Confidence)

- I developed a better understanding of the pathophysiology of the conditions in the SCE (Learning)

- My assessment skills improved (Learning)

- I feel more confident in my decision-making skills (Confidence)

- I developed a better understanding of the medications that were in the SCE (Learning)

- The instructor's questions helped me to critically think (Learning)

- I feel better prepared to care for real patients (Confidence)

- I am able to better predict what changes may occur with my real patients (Confidence)

- I am more confident in determining what to tell the health care provider (Confidence)

- Completing the SCE helped me understand classroom information better (Learning)

- I was challenged in my thinking and decisionmaking skills (Learning)

- I learned as much from observing my peers as I did when I was actively involved in caring for the simulated patient (Learning)

- Debriefing and group discussion were valuable (Learning)

\section{Rationale for Item Change}

- Prebriefing a new concept since original SET development; INACSL Standard IV: Facilitation

- Changed to be an active item: respond vs recognize; QSEN Patient-Centered Care BSN Essential IX: Baccalaureate Generalist Nursing Practice

- "of the conditions in the SCE" unnecessary since SET-M completed after each SCE

- Tool assesses perception of confidence, not actual skill performance; QSEN PatientCentered Care

- Changed to be more active; QSEN

Teamwork \& Collaboration; BSN Essential VI: Interprofessional Communication and Collaboration for Improving Patient Health Outcomes

- "that were in the SCE" unnecessary

- Focus on learner instead of instructor Change wording from "critical thinking" to "clinical decision-making skills"; QSEN Patient-Centered Care; BSN Essential IX: Baccalaureate Generalist Nursing Practice

-Wording more specific: from "prepare" to "prioritize"; from "care" to "interventions"; QSEN Patient-Centered Care; BSN Essential IX: Baccalaureate Generalist Nursing Practice

-Subsumed in other items

-BSN Essential IX: Baccalaureate Generalist Nursing Practice

-BSN Essential VII: Clinical Prevention and Population Health

- More active wording; change from "provider" to "team"; QSEN Teamwork \& Collaboration; BSN Essential VI: Interprofessional Communication and Collaboration for Improving Patient Health Outcomes

- Deleted

- Subsumed in other items

- QSEN Safety; BSN Essential II: Basic Organizational and Systems Leadership for Quality Care \& Patient Safety

- Deleted

- QSEN Evidence-Based Practice; BSN Essential III: Scholarship for Evidence-Based Practice

- Additional focus on components of debriefing that had not been as clear when SET developed; INACSL Standard VI: The Debriefing Process

\section{New SET-M (with Subscales)}

-Prebriefing increased my confidence. (Prebriefing)

-Prebriefing was beneficial to my learning. (Prebriefing)

I am better prepared to respond to changes in my patient's condition. (Learning)

- I developed a better understanding of the pathophysiology. (Learning)

- I am more confident of my nursing assessment skills. (Learning)

- I felt empowered to make clinical decisions. (Learning)

- I developed a better understanding of medications. (Leave blank if no medications in scenario) (Learning)

- I had the opportunity to practice my clinical decision-making skills. (Learning)

- I am more confident in my ability to prioritize care and interventions. (Confidence)

I am more confident in communicating with my patient. (Confidence)

- I am more confident in my ability to teach patients about their illness and interventions. (Confidence)

- I am more confident in my ability to report information to health care team. (Confidence)

- I am more confident in providing interventions that foster patient safety. (Confidence)

- I am more confident in using evidence-based practice to provide nursing care. (Confidence)

- Debriefing contributed to my learning. (Debriefing)

- Debriefing allowed me to verbalize my feelings before focusing on the scenario. (Debriefing)

- Debriefing was valuable in helping me improve my clinical judgment. (Debriefing)

- Debriefing provided opportunities to selfreflect on my performance during simulation. (Debriefing)

- Debriefing was a constructive evaluation of the simulation. (Debriefing) 
measuring performance. In simulation, both the performance of the facilitator and the student may lead to variability of outcomes. In this environment, the patient responds to the actions or inactions of the learners, potentially leading to a variety of outcomes. KardongEdgren et al. (2010) suggest that researchers refine currently available instruments, using larger and more diverse populations, rather than create additional tools that lack demonstrated reliability and validity.

\section{METHOD}

To document student perceptions of how effective the simulation experience has been, the SET had been completed by students in one multicampus college of nursing in the United States at the end of each SCE. Faculty used these evaluations to make changes to the simulation experience, if indicated. Shortly after the release of the INACSL Standards, college simulation leaders met to discuss the use of the SET as an evaluation tool in their simulation program. This meeting led to comments that certain areas, such as prebriefing, were not highlighted in the SET, as this terminology was developed after the instrument was created. The educators recommended changing the wording of some items and adding others, specifically to the debriefing section.

The modified instrument was renamed the Simulation Effectiveness Tool-Modified (SET-M). A plan was formulated to reevaluate the psychometric properties of the SET-M for evaluating simulation effectiveness under current standards.

\section{Original Tool}

The SET was developed to address the lack of valid and reliable instruments to assess the effectiveness of simulation experiences in nursing education (Elfrink Cordi et al., 2012). Its purpose was to assess how well simulation met student learning needs. The SET was assembled from informal evaluation tools used by several schools of nursing that were involved in the development of the Program for Nursing Curriculum Integration (PNCI), a vender-developed simulation curriculum (Medical Education Technologies [METI],

\section{Table 2: Demographic Characteristics}

\begin{tabular}{|c|c|}
\hline Characteristic & n (\%) \\
\hline \multicolumn{2}{|l|}{ Gender } \\
\hline Female & $1003(77.9 \%)$ \\
\hline Male & $161(12.5 \%)$ \\
\hline Missing & $124(9.6 \%)$ \\
\hline \multicolumn{2}{|l|}{ Ethnicity } \\
\hline White & $532(41.3 \%)$ \\
\hline Black/African American & $369(28.6 \%)$ \\
\hline Latino & $161(12.5 \%)$ \\
\hline Asian & $148(11.5 \%)$ \\
\hline Native Hawaiian/Pacific Islander & $32(2.5 \%)$ \\
\hline American Indian/Alaska Native & $10(0.8 \%)$ \\
\hline Missing & $36(2.8 \%)$ \\
\hline \multicolumn{2}{|l|}{ Level in Program } \\
\hline Freshman & $16(1.2 \%)$ \\
\hline Sophomore & $247(19.2 \%)$ \\
\hline Junior & $581(45.1 \%)$ \\
\hline Senior & $420(32.6 \%)$ \\
\hline Missing & $24(1.9 \%)$ \\
\hline \multicolumn{2}{|l|}{ Worked as Nursing Assistant } \\
\hline No & $736(57.1 \%)$ \\
\hline Yes & $480(34.3 \%)$ \\
\hline Missing & $72(5.6 \%)$ \\
\hline \multicolumn{2}{|l|}{ Time Worked } \\
\hline None & $51(4.0 \%)$ \\
\hline Less than 1 year & $87(6.8 \%)$ \\
\hline 1-2 Years & $153(11.9 \%)$ \\
\hline 3-4 Years & $113(8.8 \%)$ \\
\hline 5 or more years & $133(10.3 \%)$ \\
\hline
\end{tabular}

2005). SET developers used content analysis of the informal tools to synthesize items deemed important for assessing simulation.

An exploratory factor analysis (EFA) was conducted on the 20-item instrument with a convenience sample of 200 students (Elfrink Cordi et al., 2012). Several measurement items were dropped for various reasons, leaving 13 items, which loaded onto two subscales: Learning and Confidence. Evaluation scales were also changed from a five-point scale to a three-point scale. The instrument was administered to a multisite sample of 645 students. The Confidence $(\alpha=.88)$ and Learning $(\alpha=.87)$ subscales, as well as the instrument overall $(\alpha=.93)$, demonstrated acceptable internal consistency.

\section{Modified Tool}

The original 13 items of the SET were in creased to 19 items for the SET-M. Changes were made to items as a result of several factors. (See Table 1.) In some cases, as with prebriefing and debriefing, additional information learned about this part of the SCE had 


\section{Table 3: Measurement Item Descriptive Statistics}

\begin{tabular}{|c|c|c|c|c|c|c|}
\hline No. & Item & $\begin{array}{l}\text { Do Not } \\
\text { Agree }\end{array}$ & $\begin{array}{l}\text { Somewhat } \\
\text { Agree }\end{array}$ & $\begin{array}{l}\text { Strongly } \\
\text { Agree }\end{array}$ & Mean (SD) & MSA \\
\hline 1 & Prebriefing increased my confidence & $25(1.9 \%)$ & $226(17.5 \%)$ & 1035 (80.4\%) & $2.79(.46)$ & 0.83 \\
\hline 2 & Prebriefing was beneficial to my learning & $15(1.2 \%)$ & $155(12.0 \%$ & $1116(86.6 \%)$ & $2.86(.38)$ & 0.82 \\
\hline 3 & $\begin{array}{l}\text { I am better prepared to respond to changes } \\
\text { in my patient's condition }\end{array}$ & $3(.2 \%)$ & $232(18.0 \%)$ & $1036(80.4 \%)$ & $2.81(.40)$ & 0.95 \\
\hline 4 & $\begin{array}{l}\text { I developed a better understanding of the } \\
\text { pathophysiology }\end{array}$ & $26(2.0 \%)$ & $292(22.7 \%)$ & $970(75.3 \%)$ & $2.73(.49)$ & 0.94 \\
\hline 5 & $\begin{array}{l}\text { I am more confident of my nursing } \\
\text { assessment skills }\end{array}$ & $17(1.3 \%)$ & $278(21.6 \%)$ & $993(77.1 \%)$ & $2.76(.46)$ & 0.95 \\
\hline 6 & I felt empowered to make clinical decisions & $23(1.8 \%)$ & $326(25.3 \%)$ & $939(72.9 \%)$ & $2.71(.49)$ & 0.94 \\
\hline 7 & $\begin{array}{l}\text { I developed a better understanding of } \\
\text { medications }\end{array}$ & $38(3.0 \%)$ & $272(21.1 \%)$ & $871(67.6 \%)$ & $2.71(.52)$ & 0.97 \\
\hline 8 & $\begin{array}{l}\text { I had the opportunity to practice my clinical } \\
\text { decision-making skills }\end{array}$ & $13(1.0 \%)$ & $208(16.1 \%)$ & $1066(82.8 \%)$ & $2.82(.41)$ & 0.96 \\
\hline 9 & $\begin{array}{l}\text { I am more confident in my ability to } \\
\text { prioritize care and interventions }\end{array}$ & $16(1.2 \%)$ & $241(18.7 \%)$ & $1030(80.0 \%)$ & $2.79(.44)$ & 0.96 \\
\hline 10 & $\begin{array}{l}\text { I am more confident in communicating with } \\
\text { my patient }\end{array}$ & $22(1.7 \%)$ & $189(14.7 \%)$ & $1077(83.6 \%)$ & $2.82(.43)$ & 0.95 \\
\hline 11 & $\begin{array}{l}\text { I am more confident in my ability to teach } \\
\text { patients about their illness and interventions }\end{array}$ & $21(1.6 \%)$ & $244(18.9 \%)$ & $1023(79.4 \%)$ & $2.78(.45)$ & 0.96 \\
\hline 12 & $\begin{array}{l}\text { I am more confident in my ability to report } \\
\text { information to health care team }\end{array}$ & $17(1.3 \%)$ & $227(17.6 \%)$ & $1044(81.1 \%)$ & $2.80(.43)$ & 0.95 \\
\hline 13 & $\begin{array}{l}\text { I am more confident in providing } \\
\text { interventions that foster patient safety }\end{array}$ & $16(1.2 \%)$ & $214(16.6 \%)$ & $1057(82.1 \%)$ & $2.81(.42)$ & 0.96 \\
\hline 14 & $\begin{array}{l}\text { I am more confident in using evidence- } \\
\text { based practice to provide nursing care }\end{array}$ & $28(2.2 \%)$ & $244(18.9 \%)$ & $1016(78.9 \%)$ & $2.77(.47)$ & 0.93 \\
\hline 15 & Debriefing contributed to my learning & $7(.5 \%)$ & $115(8.9 \%)$ & $1165(90.5 \%)$ & $2.90(.32)$ & 0.95 \\
\hline 16 & $\begin{array}{l}\text { Debriefing allowed me to verbalize my } \\
\text { feelings before focusing on the scenario }\end{array}$ & $12(.9 \%)$ & $143(11.1 \%)$ & $1132(87.9 \%)$ & $2.87(.36)$ & 0.92 \\
\hline 17 & $\begin{array}{l}\text { Debriefing was valuable in helping me } \\
\text { improve my clinical judgment }\end{array}$ & $6(.5 \%)$ & $118(9.2 \%)$ & 1163 (90.3\%) & $2.90(.32)$ & 0.93 \\
\hline 18 & $\begin{array}{l}\text { Debriefing provided opportunities to self- } \\
\text { reflect on my performance during simulation }\end{array}$ & $7(.5 \%)$ & $112(8.7 \%)$ & 1168 (90.7\%) & $2.90(.32)$ & 0.92 \\
\hline 19 & $\begin{array}{l}\text { Debriefing was a constructive evaluation of } \\
\text { the simulation }\end{array}$ & $6(.5 \%)$ & 115 (8.9\%) & $1166(90.5 \%)$ & $2.90(.31)$ & 0.9 \\
\hline
\end{tabular}

not been identified when the SET was created. The Standards of Best Practice: Simulation (Decker et al., 2013; Franklin et al., 2013) guided the development of these items.

Other items were changed to take on a more active focus. For example, the wording of one item was changed to reflect that the learner was prepared to respond to a patient change, rather than just recognize that change. Quality and Safety Education for Nurses (QSEN) competencies (Cronewett et al., 2007) and concepts from the Essentials of Baccalaureate Education for Professional Nursing Practice (American Association of Colleges of Nursing, 2008) were considered when items were changed or developed.

\section{Sampling and Recruitment}

Institutional review board approval at two baccalaureate colleges of nursing was obtained to conduct the study. Data were collected for the EFA using a cross-sectional survey design. A minimum sample size of 1,000 participants was chosen for this study based on the desire to have 10 responses per 
survey item, with an anticipated response rate of 20 percent. The literature varies widely with regard to sample sizes and subject-toitem ratios for survey development and factor analysis (Osborne \& Costello, 2004).

Undergraduate nursing students in the medical-surgical semester of the program were recruited for participation. Inclusion criteria were: students needed to be 18 to 65 years of age, read and write English well enough to complete the study instrument, and participate in a nursing clinical simulation experience during the semester.

The SET was already utilized at both colleges, with the expectation that students complete the tool following each SCE. Students were given an informed consent form after completing the debriefing portion of an SCE; they were informed they could opt out of participating in the study while fulfilling course evaluation requirements.

The SET-M questionnaire was completed online using Learning Space ${ }^{\circledR}$ (CAE Healthcare) at one college and SurveyMonkey ${ }^{\circledR} \quad$ (www.surveymonkey.com) at the other. Data were downloaded into an Excel spreadsheet, then transferred to SPSS version 22 for analysis. Descriptive statistics were calculated for demographic characteristics and study variables. EFA was used to explore the factor structure of the data.

\section{RESULTS}

\section{Participants}

Demographic characteristics for study participants are reported in Table 2. All participants were over 18 years of age. A total of 1,288 individuals from 13 different campuses completed the online survey; most were female and a large proportion reported being white. Most had not worked in a nursingrelated position (e.g., nursing assistant or LPN) before participating in the study.

\section{Exploratory Factor Analysis}

Descriptive statistics for individual items are reported in Table 3. Means were near the highest value of the scale for all items. Frequencies for all items showed that most participants strongly agreed with all statements. All items were negatively skewed, with few participants disagreeing with instrument statements.

All but two items had very few missing values (two or less). The third item, about being better prepared to respond to changes in patient condition, was missing 17 responses (1.3 percent), which did not seem to be of concern. However, the seventh item, about understanding medications, was missing 107 responses (8.3 percent). Since this was a significant number and we had a large sample size, the decision was made to proceed with the EFA using the SPSS default of list-wise deletion to handle missing data (leaving $n=$ 1,165).

Inter-item correlations were reviewed. No excessively high correlations (>.8) were noted. There were a few low correlations $(<.3)$ (Pett, Lackey, \& Sullivan, 2003), but no correlations were below .2 and no items had consistently low correlations with all other items. Bartlett's test of sphericity was significant $\left(\chi^{2}\right.$ $=14377, d f=171, p=.000)$ indicating the correlation matrix was not an identity matrix and could be factored. The Kaiser-MeyerOlkin Test $(\mathrm{KMO})=.936$, which tests overall sampling adequacy, was deemed favorable to proceed with factor analysis (Pett et al.). Individual measures of sampling adequacy (MSA) are reported in Table 3 and were adequate to proceed with factor analysis.

Since all items were negatively skewed, unweighted least squares (ULS) was chosen for factor extraction, which is considered appropriate when data are not normally distributed (Nunnally \& Bernstein, 1994). Initial factor extraction using eigenvalue $>1$ as a cutoff indicated a three-factor solution. The scree plot was examined, which also seemed to indicate a three-factor solution. Different rotations were examined to clarify factor loadings and assess theoretical utility (Pett et al., 2003). A varimax rotation resulted in a three-factor solution where all items loaded strongly on a single factor (>.6).

Factor 1 items related to the simulation itself, Factor 2 items to debriefing questions, and Factor 3 items to the prebriefing. The original SET consisted of 13 items with two subscales, Confidence and Learning; only one of the original items asked about debriefing and no items asked about prebriefing. The SET-M added two new prebriefing items and expanded debriefing items to five. Both the original SET and the modified SET-M have similar items asking about student simulation experience.

A four-factor solution was attempted to see if SET-M simulation items divided into subscales. The four-factor solution with varimax rotation had prebriefing and debriefing items loading on separate factors with simulation items loading on the two remaining factors. Factor 1 explained 47.8 percent of the variance; Factor 2 explained 11.2 percent of the variance; Factor 3 explained 6.4 percent of the variance; and Factor 4 explained 4.7 percent of the variance. Factor interpretation was accomplished using the factor structure matrix as recommended by Pett et al. (2003).

- Items 9 through 14 loaded most strongly on Factor 1; those items all inquired about student confidence regarding simulation elements. That factor corresponded with the Confidence subscale of the original SET instrument; the original subscale name was retained and Factor 1 was labeled Confidence.

- Items 15 through 19 loaded most strongly on Factor 2 with low loadings on all other factors. Those items asked about the debriefing phase of simulation. That factor was labeled Debriefing.

- Items 1 and 2 loaded strongly on Factor 3, with low loadings on all other factors. Those items asked about the prebriefing phase of simulation. That factor was labeled Prebriefing.

- Items 3 through 7 loaded most strongly on Factor 4. Those items inquired about mastery of elements of providing nursing care. That factor corresponded with the Learning subscale of the original SET instrument. The original name was retained and Factor 4 was labeled Learning.

Item 8 asked about practicing clinical decision making skills. That item loaded almost evenly on Factors 1 and 4 (the simulation 
factors) and the loadings were midlevel for both (.598 and .590, respectively). It was decided to group the item with the Learning subscale (Factor 4) since it was the only item loading on Simulation Confidence that did not mention confidence. Final scores for subscales and the instrument overall are calculated by summing the relevant items.

\section{Reliability}

Internal consistency reliability was assessed for subscales and the instrument overall. The Prebriefing subscale consists of two items. Internal consistency reliability was acceptable $(\alpha=.833)$. The Learning subscale consists of six items. Internal consistency reliability was acceptable $(\alpha=.852)$; Cronbach's alpha would be reduced if any of the items were deleted. The Confidence subscale consists of six items. Internal consistency reliability was good $(\alpha=.913)$; Cronbach's alpha would be reduced if any of the items were deleted. The Debriefing subscale consists of five items. Internal consistency reliability was good $(\alpha$ $=.908)$; Cronbach's alpha would be reduced if any of the items were deleted. The SET-M overall consists of 19 items. Overall internal consistency reliability was good $(\alpha=.936)$.

\section{DISCUSSION}

The revisions made to the items on the original tool were consistent with updated terminology, greater understanding of simulation as a teaching strategy, and expectations of undergraduate nursing education in general as described by QSEN and the AACN essentials of baccalaureate education (2008). Both QSEN and the BSN essentials are commonly incorporated into course learning objectives for nursing programs. By using similar wording and intent, these changes will allow educators to more easily correlate findings in the simulation education environment with those of the traditional clinical environment and classroom evaluations.

Most instrument items had one or two missing values, meaning that only one or two people did not answer the question. However, the medication item (No. 7) had 107 missing values. The SPSS default for handling missing values in EFA is listwise deletion, meaning that responses are removed from the analysis. In this study, because we had so many participants, it was not a problem to drop these responses. However, the fact that one question alone was responsible for missing values that approached almost 10 percent of the total was a concern and brings up an interesting issue when evaluating nursing simulation. Should something like medications be part of the evaluation? The main reason to include administering medications is that it is an extremely common activity for nurses. However, the activity is not universal, and not all nursing scenarios involve medications. The investigators had to consider what should be included so that the instrument is as broadly applicable as possible, and what should be left out, to avoid problems with missing data.

Another issue that arises is how should missing data from an item of this nature be handled? It was decided that the medication item should be retained as part of the instrument since medication administration was considered by the team members to be an integral aspect of providing nursing care and removing the item would reduce content validity. A possible option for dealing with conceptually difficult items suggested by Pett et al. (2003) is to move them to their own factor so they don't cause problems with the original factor. However, the research team decided to leave the medication item in the original Learning factor to maintain instrument consistency.

There are several ways to deal with missing data, each with benefits and drawbacks. Missing data can be deleted (the default in SPSS). The benefit is that deletion is easy to do, but the drawback is loss of participants. If the sample size is significantly reduced, power can be significantly reduced. Mean substitution is another option that is also fairly easy to do. It helps retain a larger number of participants in the analysis but is shown to reduce variability and cause biased estimates, which get worse the more missing data are imputed (Eekhout et al., 2014; Shrive, Stuart, Quan, \& Ghali, 2006).

A third option is treating the missing value as a zero value. It is also easy to do and participants are retained in the analysis. The drawback is that participants with missing scores will have slightly lower final scores and it is probably a biased estimate. Multiple imputation (MI), shown to be the best method statistically (Eekhout et al., 2014; Shrive et al., 2006), is a final option. The drawback is that $\mathrm{MI}$ is a more complex procedure to perform and analyze. It is not included as a base option in SPSS, so additional software is required, and it may be out of reach for some researchers without advanced statistical support.

It is not clear why so many individuals did not respond to the medication item. It may be that some simulations did not involve medications so participants felt the item was not applicable. It may be that participants did not respond because they felt ambiguous about the item. When using SET-M, investigators and simulation coordinators should have a plan to deal with missing data from the medication item. If the simulation being evaluated does not involve a medication component, imputing a zero value for that item may be appropriate. If the simulation involves a medication component the best choice statistically is MI, but deletion and mean substitution are options offered by many statistical packages.

Note should be made of the difference between factor pattern and structure matrices in this EFA. When factors are orthogonal, factor pattern loadings and factor structure loadings are equivalent (Pett et al., 2003). However, when factors are not orthogonal, as was seen in this analysis, larger correlations between factors result in greater differences between pattern and structure factor loadings (Pett et al.). Factor structure loadings represent simple correlations between items and factors not controlling for other items; pattern structure loadings represent partial correlations controlling for correlations between factors. Some researchers prefer interpreting factors using the structure factor matrix because it is more stable in light of correlations between factors, although interpretation can be more difficult (Pett et al., 2003). That was the strategy employed in this study.

\section{CONCLUSION}

The SET-M demonstrates construct validity and a similar factor structure to the 
original SET instrument with the addition of Prebriefing and Debriefing constructs when used to evaluate nursing simulations. It also demonstrates acceptable levels of internal consistency for all subscales and for the instrument overall.

While it is important to develop new tools to evaluate outcomes in simulation education, it is also vital that tools currently in use be kept up to date. As has been shown in this article, significant changes have occurred in the past decade that further define our understanding of best practices when facilitating learning with manikin-based simulation. The SET-M has been shown to be a valid and reliable method of evaluating students' perceptions of the effectiveness of learning in the simulation environment. The results of the SET-M can be used by educators to improve the design and implementation of the SCE to further enhance outcomes.

\section{ABOUT THE AUTHORS}

Kim Leighton, $\mathrm{PhD}, \mathrm{RN}, \mathrm{ANEF}$, is assistant dean of research and simulation faculty development, DeVry Medical International's Institute for Research \& Clinical Strategy, Iselin, New Jersey. Patricia Ravert, PhD, $\mathrm{RN}$, CNE, FAAN, ANEF, is dean and professor, Brigham Young University College of Nursing, Provo, Utah. Vickie Mudra, BA, is national director of clinical learning resources,
Chamberlain College of Nursing, Downers Grove, Illinois. Christopher Macintosh, BSN, $\mathrm{RN}$, is a $\mathrm{PhD}$ candidate, University of Utah College of Nursing. The authors acknowledge Dr. Julia Ann Raithel, professor, Chamberlain College of Nursing, for her work in helping to develop and revise SET-M items, and Deb Long, manager, SIMCARE Operations, Chamberlain College, for her assistance with data collection. Contact Dr. Leighton at kleighton@devry.edu.

\section{KEY WORDS}

Simulation Effectiveness Tool - Tool Development - Simulated Clinical Experience

\section{REFERENCES}

American Association of Colleges of Nursing. (2008). The essentials of baccalaureate education for professional nursing practice. Retrieved from www.aacn.nche.edu/education-resources/essential-series

Cook, D. A., Hatala, R., Brydges, R., Zendejas, B., Szostek, J. H., Want, A. T., ... Hamstra, S. J. (2011). Technology enhanced simulation for health professions education: A systematic review and metaanalysis. Journal of the American Medical Association, 306(9), 978-988. doi:10.1001/jama.2011.1234

Cronenwett, L., Sherwood, G., Barnsteiner, J., Disch, J., Johnson, J., Mitchell, P., . . Warren, J. (2007). Quality and safety education for nurses. Nursing Outlook, 55(3), 122-131. doi:10.1016/j. outlook.2007.02.006

Decker, S., Fey, M., Sideras, S., Caballero, S., Rockstraw, L., Boese, T., . . Borum, J. C. (2013). Standards of Best Practice: Simulation standard VI: The debriefing process. Clinical Simulation in Nursing, 9(6), S26-S29. doi:10.1016/j.ecns.2013.04.008

Eekhout, I., de Vet, H. C. W., Twisk, J. W. R., Brand, J. P. L., de Boer, M. R., \& Heymans, M. W. (2014). Missing data in a multi-item instrument were best handled by multiple imputation at the item score level. Journal of Clinical Epidemiology, 67(3), 335-342. doi:10.1016/j.jclinepi.2013.09.009

Elfrink Cordi, V. L., Leighton, K., Ryan-Wenger, N., Doyle, T. J., \& Ravert, P. (2012). History and development of the Simulation Effectiveness Tool (SET). Clinical Simulation in Nursing, 8(6), e199-e210. doi:10.1016/j.ecns.2011.12.001

Franklin, A. E., Boese, T., Gloe, D., Lioce, L., Decker, S., Sando, C. R., ... Borum, J. C. (2013). Standards of Best Practice: Simulation standard IV: Facilitation. Clinical Simulation in Nursing, 9(6), S19-S21. doi:10.1016/j.ecns.2013.04.011

Hayden, J. K., Smiley, R. A., Alexander, M., Kardong-Edgren, S., \& Jeffries, P. R. (2014). The NCSBN national simulation study: A longitudinal, randomized, controlled study replacing clinical hours with simulation in prelicensure nursing education. Journal of Nursing Regulation, 5(2), Suppl, S3-S40. doi:10.1016/S21558256(15)30062-4
INACSL Board of Directors. (2013). Standards for best practice: Simulation. Clinical Simulation in Nursing, 9(6), Suppl, Si-S32. doi:10.1016/j.ecns.2013.05.008

Kardong-Edgren, S., Adamson, K. A., \& Fitzgerald, C. (2010). A review of currently published evaluation instruments for human patient simulation. Clinical Simulation in Nursing, 6(1), e25-e35.

Lapkin, S., Levett-Jones, T., Bellchambers, H., \& Fernandez, R. (2010). Effectiveness of patient simulation manikins in teaching clinical reasoning skills to undergraduate nursing students: A systematic review. Clinical Simulation in Nursing, 6(6), e207-e222. doi:10.1016/j.ecns.2010.05.005

McGaghie, W. C., Issenberg, S. B., Petrusa, E. R., \& Scalese, R. J. (2010). A critical review of simulation-based medical education research: 2003-2009. Medical Education, 44(1), 50-63. doi:10.1111/j.1365-2923.2009.03547.x

Medical Education Technologies, Inc. (METI). (2005). Program for nursing curriculum integration. Sarasota, FL: Author.

Nehring, W. M. (2010). History of simulation in nursing. In W. M. Nehring \& F. R. Lashley (Eds.), High-fidelity patient simulation in nursing education (pp. 3-26). Sudbury, MA: Jones \& Bartlett.

Nunnally, J. C., \& Bernstein, I. H. (1994). Psychometric theory (3rd ed.). New York, NY: McGraw-Hill.

Osborne, J. W., \& Costello, A. B. (2004). Sample size and subject to item ratio in principal components analysis. Practical Assessment, Research \& Evaluation, 9(11). Retrieved from http://PAREonline. net/getvn.asp?v=9\&n=11

Pett, M. A., Lackey, N. R., \& Sullivan, J. J. (2003). Making sense of factor analysis: The use of factor analysis for instrument development in healthcare research. Thousand Oaks, CA: Sage.

Shrive, F. M., Stuart, H., Quan, H., \& Ghali, W. A. (2006). Dealing with missing data in a multi-question depression scale: A comparison of imputation methods. BMC Medical Research Methodolology, 6 , 57. doi:10.1186/1471-2288-6-57 
Copyright of Nursing Education Perspectives is the property of National League for Nursing and its content may not be copied or emailed to multiple sites or posted to a listserv without the copyright holder's express written permission. However, users may print, download, or email articles for individual use. 